\title{
OPTIMISASI KINERJA MESIN PENGOLAHAN TANDAN BUAH SEGAR MENGGUNAKAN METODE RCCP (STUDI KASUS PT. KARYA TANAH SUBUR)
}

\author{
Abdul Malik Ali ${ }^{1}$, Arie Saputra ${ }^{2}$, Junianto Putra ${ }^{3}$ \\ ${ }^{1}$ Jurusan Teknik Industri, F. TEKNIK Universitas Teuku Umar \\ ${ }^{2}$ Jurusan Teknik Industri, F. TEKNIK Universitas Teuku Umar \\ ${ }^{3}$ Jurusan Teknik Industri, F. TEKNIK Universitas Teuku Umar \\ E-mail: '1malikaliabdul@yahoo.com
}

\begin{abstract}
Successful planning and production controls require active capacity planning, in order to be able to meet the established master production schedules. Lack of capacity will lead to production failures, delays in delivery to customers, and loss of confidence in the formal system resulting in a decreased corporate reputation. Overcapacity will result in low resource utilities, increased costs, product prices become competitive, decreased profits. Standard time is a measure of completion of a production process for one unit of product with justified clearance. The standard time required to process 40 Ton bunches of palm fruit sterilizer is 94.70 minute/unit, for thresher machine 73,31 minutes/unit, for screw press machine 96,48 Minutes / unit, and oil purification machine 147,13 minute/unit. Efficiency is the ability of the machine to produce a product. The efficiency of sterilizer machine is $88.00 \%$, for thresher machine is $88.00 \%$, for screw press machine is $88.80 \%$, and oil purification machine is $74.00 \%$. Machine utility is the percentage of machine usage in units of time. The sterilizer machine utility is $81,33 \%$, for thresher machine is $87,35 \%$, for screw press machine is $86,88 \%$, and oil purification machine is $83,18 \%$. Capacity is the rate of output per unit time indicating that the facility theoretically has the ability to produce it. The sterilizer machine capacity is 81.33 ton/hour, for thresher bumper machine is 45,08 ton/hour, for screw press machine is 119,09 ton/hour, and oil purification machine is 79,49 ton/hour. The average production capacity of machine taken for two years is 27.61 ton/hour with machine capacity optimization level of 51,88 ton/hour.
\end{abstract}

Keywords : Production Planning and Control, Standard Time, Capacity (RCCP).

\section{PENDAHULUAN}

Kinerja merupakan hasil kerja secara kualitas dan kuantitas yang dicapai oleh seseorang karyawan dalam melaksanakan tugasnya sesuai dengan tanggung jawab yang diberikan kepadanya. Sedangkan yang dimaksud dengan kinerja mesin adalah prestasi dari 
suatu mesin yang erat hubungannya dengan daya mesin yang dihasilkan serta daya guna dari mesin tersebut [1].

Peranan kinerja terhadap pengolahan produksi merupakan suatu hal yang sangat penting dalam manajemen operasi, karena tidak ada sesuatu yang dapat diselesaikan tanpa manusia yang mengerjakan yang ditunjang dengan peralatan (mesin). Peranan tenaga kerja dan peralatan (mesin) bila dikelola dengan baik dan efisien adalah kunci keberhasilan dari bagian manajemen operasi.

Mesin merupakan alat bantu untuk melakukan proses transformasi atau proses pengolahan dari masukan (input) menjadi keluaran (output). Mesin sangat memegang peranan penting dalam proses pengolahan, karena tanpa adanya mesin proses produksi tidak akan efisien, juga hasil yang didapat tidak optimal. Kapasitas mesin terdiri dari kapasitas terpasang dan kapasitas terpakai. Kapasitas terpasang merupakan jumlah maksimum dari bahan baku yang dapat diolah oleh mesin tersebut. Sedangkan kapasitas terpakai merupakan jumlah minimum dari bahan baku yang dapat diolah oleh mesin [2].

Pengendalian produksi dan perencanaan kapasitas yang diterapkan oleh PT. Karya Tanah subur adalah dengan perhitungan kapasitas unit, namun dari perhitungan kapasitas unit yang diterapkan masih kurang efektifnya dalam mengurangi bahan baku yang menumpuk. Sehingga Keberhasilan perencanaan dan pengendalian produksi memerlukan perencanaan kapasitas yang aktif, agar mampu memenuhi jadwal induk produksi yang ditetapkan. Seirirng naiknya laju produksi CPO PT. Karya Tanah Subur, Rough Cut Capacity Planning (RCCP) berperan dalam perencanaan prioritas kapasitas produksi yang berguna menetapkan sumber-sumber spesifik tertentu, khususnya yang diperkirakan akan menjadi hambatan potensial (Potential bottleneck), seperti yang terurai pada data restan CPO yang mengalami fluktuasi (naik turun). Pada bulan Januari 2012 jumlah restan CPO sebesar 155,165 kg. Pada bulan Februari tahun 2012 jumlah restan CPO mengalami peningkatan yaitu sebesar 158,370 kg. Pada bulan Maret tahun 2012 jumlah restan CPO mengalami peningkatan kembali yaitu sebesar 159,910 kg. Pada bulan April tahun 2012 jumlah restan CPO mengalami penurunan yaitu sebesar 153,304. Pada bulan Mei tahun 2012 jumlah restan CPO mengalami peningkatan kembali yaitu sebesar 209,653 kg. Pada bulan Juni tahun 2012 jumlah restan CPO kembali mengalami penurunan yaitu sebesar 202,844 kg. Pada bulan Juli tahun 2012 jumlah restan CPO mengalami peningkatan yaitu sebesar 218,575 kg. Pada bulan Agustus tahun 2012 jumlah restan CPO mengalami peningkatan kembali yaitu sebesar 219,653 kg. Pada bulan September 2012 jumlah restan CPO mengalami penurunan yang cukup signifikan yaitu sebesar $174,771 \mathrm{~kg}$. Pada bulan Oktober tahun 2012 jumlah restan CPO kembali mengalami peningkatan yang cukup signifikan yaitu sebesar 224,085 kg. Pada bulan November tahun 2012 mengalami penurunan yaitu sebesar 152,073, dan pada bulan Desember 2012 mengalami peningkatan kembali yaitu sebesar $204,738 \mathrm{~kg}$, begitu juga dengan tahun berikutnya nilai restan sangat berfluktuasi sehingga terjadi penurunan kapasitas produksi yang dihasilkan.

Berdasarkan data restan yang setiap bulan mengalami peningkatan secara fluktuasi ini di sebabkan karena waktu perebusan atau holding time yang terlalu lama sehingga buah sawit terlalu banyak menumpuk, maka dari itu diperlukan suatu perencanaan produksi yang baik sehingga akan tercipta nantinya suatu kondisi produksi yang optimum yang akan menyebabkan pabrik bekerja pada kapasitas yang optimal. Salah satu metode yang dapat digunakan dalam mengoptimalkan mesin pengolahan TBS dalam produksi CPO adalah metode Rough Cut Capacity Planning (RCCP). Keunggulan metode Rough Cut Capacity Planning (RCCP) yaitu menganalisis suatu proses atau evaluasi kapasitas dari fasilitas produksi yang tersedia di lantai pabrik agar sesuai atau dapat mendukung jadwal induk produksi yang akan disusun. Langkah ini sangat penting bagi pengambil kebijakan dalam membuat suatu keputusan dalam mengalokasikan sumber daya guna menghasilkan 
kapasitas pabrik yang diharapkan, sehingga dalam kekurangan kapasitas yang menyebabkan kegagalan produksi, keterlambatan pengiriman kepelanggan, dan kehilangan kepercayaan dalam sistem formal yang mengakibatkan reputasi perusahaan menurun dapat teratasi.

\section{METODE PENELITIAN}

\subsection{Jenis Penelitian}

Berdasarkan sifatnya, maka penelitian ini digolongkan sebagai penelitian deskriftif (descriptif research) yaitu penelitian yang melakukan pemecahan terhadap suatu masalah yang ada sekarang secara sistematis dan faktual berdasarkan data yang ada.

\subsection{Rancangan Penelitian}

Rancangan Penelitian dapat dilihat pada blok diagram metodologi penelitian pada gambar 1. Blok Diagram Prosedur Penelitian.

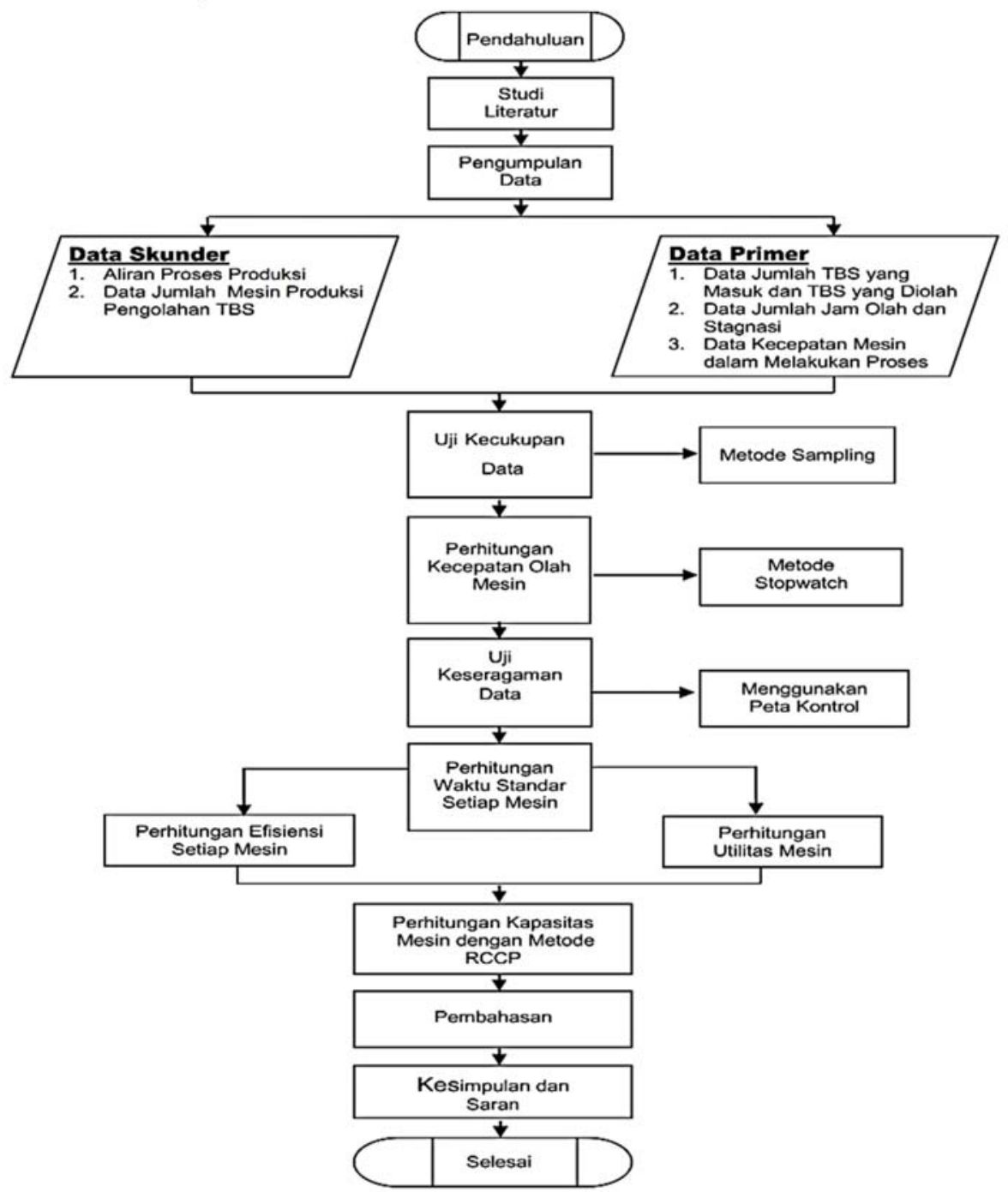

Gambar 1. Blok Diagram Prosedur Penelitian. 


\subsubsection{Pendahuluan}

Peninjauan Lapangan dilakukan untuk melihat secara nyata proses produksi dan data yang ada di dalam perusahaan serta untuk mengetahui masalah-masalah yang terjadi dilapangan. Dan masalah yang ditemui adalah kurang optimalnya proses produksi yang mengakibatkan penurunan kapasitas kinerja mesin pengolahan tandan buah segar untuk menghasilkan CPO.

\subsubsection{Studi literatur}

Studi literatur dilakukan untuk melihat atau meninjau pustaka-pustaka yang berkaitan dengan penelitian yang dilakukan atau mengumpulkan data pustaka tentang perencanaan dan pengendalian produksi, optimalisasi, kapasitas, serta metode Rough Cut Capacity Planning (RCCP) dan mempelajari teori-teori literatur yang berhubungan dengan optimalisasi.

\subsubsection{Pengumpulan Data}

Penelitian ini menggunakan beberapa metode atau teknik dan instrumen yang digunakan untuk pengumpulan data diantaranya adalah:

1. Metode observasi, yaitu syarat utama dalam metodologi penelitian, yang berguna dalam proses pengumpulan data secara sistematis dan analisis logis terhadap data atau informasi, sehingga dapat memberikan suatu kesimpulan atau diagnosis permasalahan di tempat penelitian demi mencapai suatu tujuan dalam kegiatan penelitian.

2. Teknik dokumentasi, yaitu mencatat data yang dibutuhkan pada proses pengolahan mesin sterilizer, mesin penebah, mesin screw press dan mesin pemurnian minyak untuk bahan penelitian yang ada di perusahaan.

3. Wawancara dengan pekerja tentang proses produksi.

Dalam penelitian descriptif research (pemecahan terhadap suatu masalah) wawancara menjadi metode pengumpulan data yang utama. Adapun data yang di perlukan dalam penelitian ini terbagi dalam dua bagian diantaranya adalah:

1. Data primer yang dikumpulkan dalam penelitian ini dengan melakukan pengamatan secara langsung pada daerah kerja atau tempat pengolahan tandah buah segar diantaranya meliputi data:

1) Data Jumlah Tandan Buah Segar yang masuk dan Diolah

2) Data Jumlah Jam Olah dan Stagnasi

3) Data Waktu Kecepatan Mesin dalam Melakukan Proses

4) Data Jumlah Mesin Proses Produksi Pengolahan TBS.

Adapun instrumen yang digunakan dalam pengambilan data primer adalah Stop Watch yang digunakan untuk menghitung kecepatan olah mesin-mesin produksi.

2. Data Sekunder merupakan data yang hanya dapat kita peroleh dari sumber asli perusahaan. Jika data sekunder dapat kita peroleh dengan lebih mudah dan cepat karena sudah tersedia, misalnya di perpustakaan, perusahaan-perusahaan, organisasi-organisasi perdagangan, biro pusat statistik, dan kantor-kantor pemerintah. Adapun data skunder dalam penelitian ini adalah data aliran proses produksi.

\subsubsection{Uji Kecukupan Data}

Untuk menetapkan berapa jumlah obserfasi yang seharusnya dibuat maka dilakukan uji kecukupan data untuk mengetahui apakah jumlah data yang diambil telah mencukupi untuk kemudian data tersebut dapat dilakukan pengolahannya. Apabila data tidak mencukupi, maka harus dilakukan pendataan (pengukuran) ulang sampai data 
mencukupi [3]. Adapun persamaan yang digunakan dalam menghitung uji kecukupan data digunakan rumus:

$$
N^{\prime}=\left(\frac{40 \sqrt{N \sum_{i=1}^{n} X^{2}-\left(\sum_{i=1}^{n} X_{i}\right)^{2}}}{\sum_{i=1}^{n} X_{i}}\right)^{2}
$$

Dimana: $\quad \mathrm{N}^{\prime}=$ Jumlah pengukuran yang seharusnya dilaksanakan.

$\mathrm{N}=$ Jumlah pengamatan yang dilakukan.

\subsubsection{Perhitungan Kecepatan Olah Mesin Dengan Stop Watch}

Melakukan observasi langsung terhadap mesin produksi dengan menggunakan stop watch sebagai instrumen yang digunakan.

\subsubsection{Uji Keseragaman Data}

Fungsi keseragaman data dalam penelitian ini adalah untuk mengetahui apakah data yang didapat seragam atau tidak (melebihi dari batas kontrol atas (BKA) dan batas kontrol bawah (BKB) yang telah ditentukan). Data dikatakan seragam jika berada pada batas kontrol atas dan batas kontrol bawah, dan apabila data berada berada diluar batas kontrol (data tidak seragam) maka data tersebut dibuang dan dilakukan perhitungan kembali. Adapun persamaan yang digunakan:

$$
\begin{aligned}
& \mathrm{UCL}_{\bar{x}}=\overline{\bar{X}}+2 \sigma_{x} \\
& \mathrm{LCL}_{\bar{x}}=\overline{\bar{X}}-2 \sigma_{\mathrm{x}}
\end{aligned}
$$

Dimana: $\quad$ UCL $=$ batas kontrol atas

$\mathrm{LCL}=$ batas kontrol bawah

$\Sigma \quad=$ standar deviasi dari rata-rata subgroup

\subsubsection{Perhitungan Waktu Standar Setiap Mesin}

Apabila pengukuran waktu telah selesai, yaitu semua data yang didapat memiliki keseragaman data yang dikehendaki dan jumlahnya telah memenuhi tingkat ketelitian dan keyakinan yang diinginkan maka selesai kegiatan pengukuran waktu. Langkah selanjutnya adalah mengolah data tersebut sehingga memberikan waktu baku [4]. Adapun persamaan yang digunakan merujuk pada persamaan:

1. Menghitung Waktu Standar $\left(\mathrm{W}_{\mathrm{b}}\right)$.

$W_{b}=W_{N} \times \frac{(100)}{100-\text { Allowance in Percent }}$

Dimana:

$\mathrm{W}_{\mathrm{b}}=$ Standar Time $=$ waktu standar yang ditetapkan

$\mathrm{W}_{\mathrm{N}}=$ Work Time $=$ waktu kerja yang dibutuhkan

2. Menghitung Waktu Siklus Rata-Rata $\left(\mathrm{W}_{\mathrm{s}}\right)$.

$W_{s}=\frac{\sum_{i=1}^{n} X_{i}}{N}$

$\mathrm{N}=$ jumlah data waktu seluruhnya. 
3. Menghitung Waktu Normal $\left(\mathrm{W}_{\mathrm{n}}\right)[5]$.

$W_{n}=W_{S} \times p$

$\mathrm{p}=$ faktor penyesuaian (rating performance)

\subsubsection{Perhitungan Efisiensi Setiap Mesin}

Efisiensi merupakan perbandingan yang terbaik antara input (masukan) dan output (hasil antara keuntungan dengan sumber-sumber yang dipergunakan). Adapun persamaan dalam menghitung efisiensi setiap mesin dilakukan dengan rumus [6]:

$$
\text { Efisiensi Mesin }=\frac{\text { Output }}{\text { Input }} \times 100 \%
$$

2.2.9. Perhitungan Utilitas Setiap Mesin

Utilitas merupakan total waktu operasi dibagi dengan total waktu kerja dimana dinyatakan dalam persamaan rumus [7]:

$$
\text { Utilitas Mesin }=\frac{\text { Jam Operasi }}{\text { Jam Kerja }} \times 100 \%
$$

\subsubsection{Perhitungan Kapasitas Olah Mesin}

Perhitungan dilakukan dengan menggunakan metode Rough Cut Capacity Planning (RCCP) untuk mendapatkan berapa kapasitas satu stasiun kerja per hari. Kapasitas ini dihitung dengan persamaan rumus [8]:

Kapasitas Mesin = Jumlah Mesin $x$ Jumlah Jam Kerja $\times$ Efesiensi $x$ Utilitas

\subsubsection{Pembahasan}

Data yang diperoleh pada pengumpulan data selanjutnya akan di bahas nilai kapasitas yang olah setiap mesein untuk menghasilkan suatu perencanaan produksi yang optimal. Kapasitas olah setiap mesin akan dibandingkan antara satu dengan yang lain untuk mendapatkan kapasitas olah mesin yang optimal.

\section{HASIL DAN PEMBAHASAN}

\subsection{Perhitungan Waktu Standar Setiap Mesin}

Berdasarkan hasil perhitungan waktu standar setiap mesin maka rekapitulasi hasil perhitungannya pada tabel 1 . sebagai berikut:

Tabel 1. Waktu Standar Setiap Mesin.

\begin{tabular}{lccc}
\hline \multicolumn{1}{c}{ Nama Mesin } & $\begin{array}{c}\text { Waktu Siklus Rata-Rata } \\
\text { (WS)/Jam }\end{array}$ & $\begin{array}{c}\text { Waktu Normal } \\
\text { (Wn)/Menit }\end{array}$ & $\begin{array}{c}\text { Waktu } \\
\text { Standar } \\
\text { (Wb)/Menit }\end{array}$ \\
\hline Sterilizer & 1,96 & 98,24 & 122,80 \\
Thesher/ Penebah & 2,07 & 103,57 & 129,47 \\
Screw Press & 2,48 & 124,13 & 155,16 \\
Pemurnian Minyak & 2,00 & 100,15 & 125,19 \\
Sumber: Hasil Perhitungan Waktu Standar Setiap Mesin. & &
\end{tabular}


Berdasarkan rekapitulasi hasil perhitungan waktu standar pada setiap mesin pengolahan CPO yang terlihat pada tabel 1 . diatas menunjukan bahwa nilai waktu standar tertinggi di tunjukan pada mesin press yaitu sebesar 155,16 menit, hal ini dikarekan pada stasiun press sering mengalami kerusakan pada saat proses produksi seprti rusaknya komponen seperti Screw Bunch Press, Coupling Press, Cage Press, dan Pipa Outlet Press sedangkan waktu standar yang terkecil yaitu pada mesin Sterilizer hal ini di sebabkan karena pada stasiun perebusan waktu yang digunakan sangat di optimalkan dan jarang mengalami kerusakan pada mesin.

\subsection{Perhitungan Efisiensi Setiap Mesin}

Perhitungan efisiensi setiap mesin merupakan ukuran yang menunjukkan seberapa jauh standar output yang telah ditetapkan perusahaan dapat tercapai dan seberapa jauh stasiun kerja tertentu mampu menggunakan kapasitas yang tersedia secara efisien. Adapun nilai efisiensi rata-rata setiap mesin dapat dilihat pada tabel 2. berikut.

Tabel 2. Efisiensi Rata-Rata Setiap Mesin.

\begin{tabular}{cc}
\hline Nama Mesin & Efisiensi (\%) \\
\hline Sterilizer & 88,00 \\
Thesher/ Penebah & 88,00 \\
Screw Press & 88,80 \\
Pemurnian Minyak & 74,00 \\
\hline Hasil Perhitungan Efisiensi Setiap Mesin &
\end{tabular}

Sumber: Hasil Perhitungan Efisiensi Setiap Mesin

Berdasarkan dari tabel 2. diatas nilai efisiensi rata-rata setiap mesin pengolahan tandan buah segar adalah mesin Sterilizer 88,00\%, untuk mesin Thesher/ Penebah 88,00\%, mesin Screw Press 88, sedangkan mesin pemurnian minyak nilai efisiensinya sebesar $74,00 \%$. Dari ke empat mesin pengolahan tandan buah segar nilai efisiensi tertinggi pada mesin Screw Press dan nilai efisiensi terendah pada mesin pemurnian minyak hal ini menunjukkan bahwa pada stasiun pemurnian minyak, waktu produksinya kurang dimanfaatkan dengan baik. Persentase efisiensi dari keempat mesin pengolahan tandan buah segar tersebut juga akan lebih jelas lagi diperlihatkan dalam bentuk histogram seperti yang terlihat pada gambar 2 berikut.

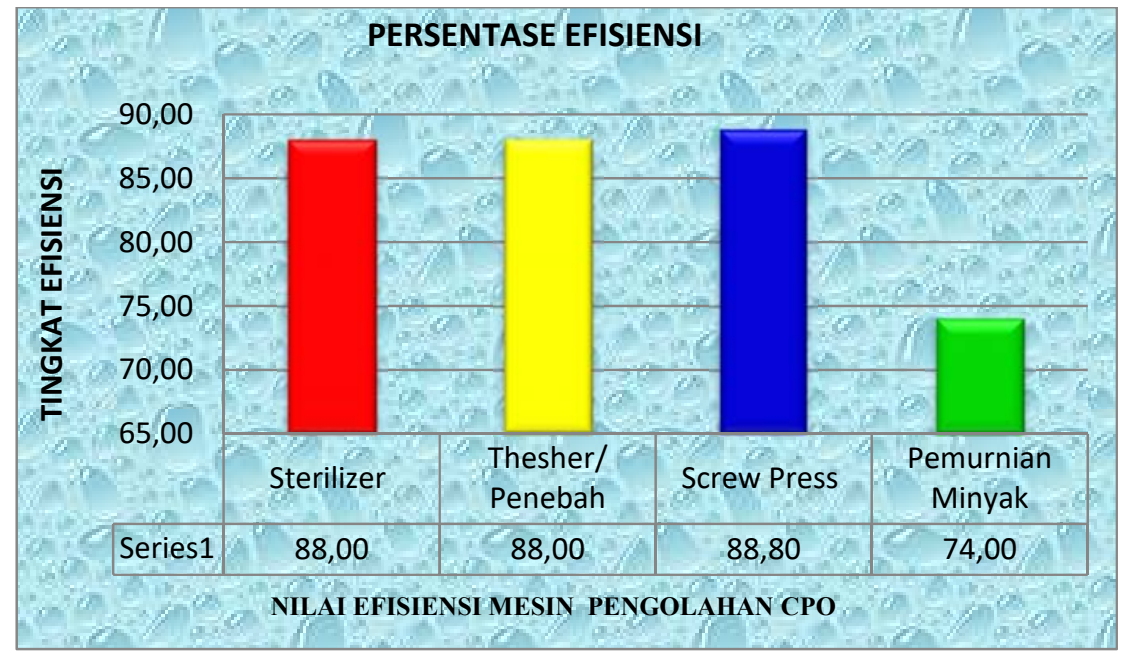

Gambar 2. Histogram Persentase Efisiensi Keempat Mesin Pengolahan Tandan Buah Segar. 


\subsection{Perhitungan Utilitas Setiap Mesin}

Utilisasi merupakan ukuran yang digunakan untuk menunjukkan seberapa intensif sumber daya atau waktu produksi dapat dimanfaatkan. Adapun nilai utilitas setiap mesin pengolahan tandan buah segar dapat dilihat pada tabel 3 berikut ini.

Tabel 3. Utilitas Rata-Rata Setiap Mesin.

\begin{tabular}{cc}
\hline Nama Mesin & Utilitas (\%) \\
\hline Sterilizer & 81,33 \\
Thesher/ Penebah & 87,35 \\
Screw Press & 86,88 \\
Pemurnian Minyak & 83,18 \\
\hline
\end{tabular}

Sumber: Hasil Perhitungan Utilitas Setiap Mesin

Utilisasi merupakan ukuran yang digunakan untuk menunjukkan seberapa intensif sumber daya atau waktu produksi dapat dimanfaatkan. Nilai utilisasi sempurna adalah $100 \%$. Tingkat utilisasi yang paling tertinggi pada mesin pengolahan tandan buah segar adalah stasiun Thesher/ Penebah yaitu 87,35\%, hal ini menunjukkan bahwa pada stasiun Thesher/ Penebah waktu produksi sudah dimanfaatkan dengan baik. Sementara tingkat utilisasi yang paling rendah adalah stasiun Sterilizer yaitu $81,33 \%$, dimana waktu produksi masih kurang dapat dimanfaatkan dengan baik sehingga perlu dilakukan peningkatan utilisasi kembali. Persentase utilitas dari keempat mesin pengolahan tandan buah segar tersebut juga akan lebih jelas lagi diperlihatkan dalam bentuk histogram seperti yang terlihat pada gambar 4 berikut.

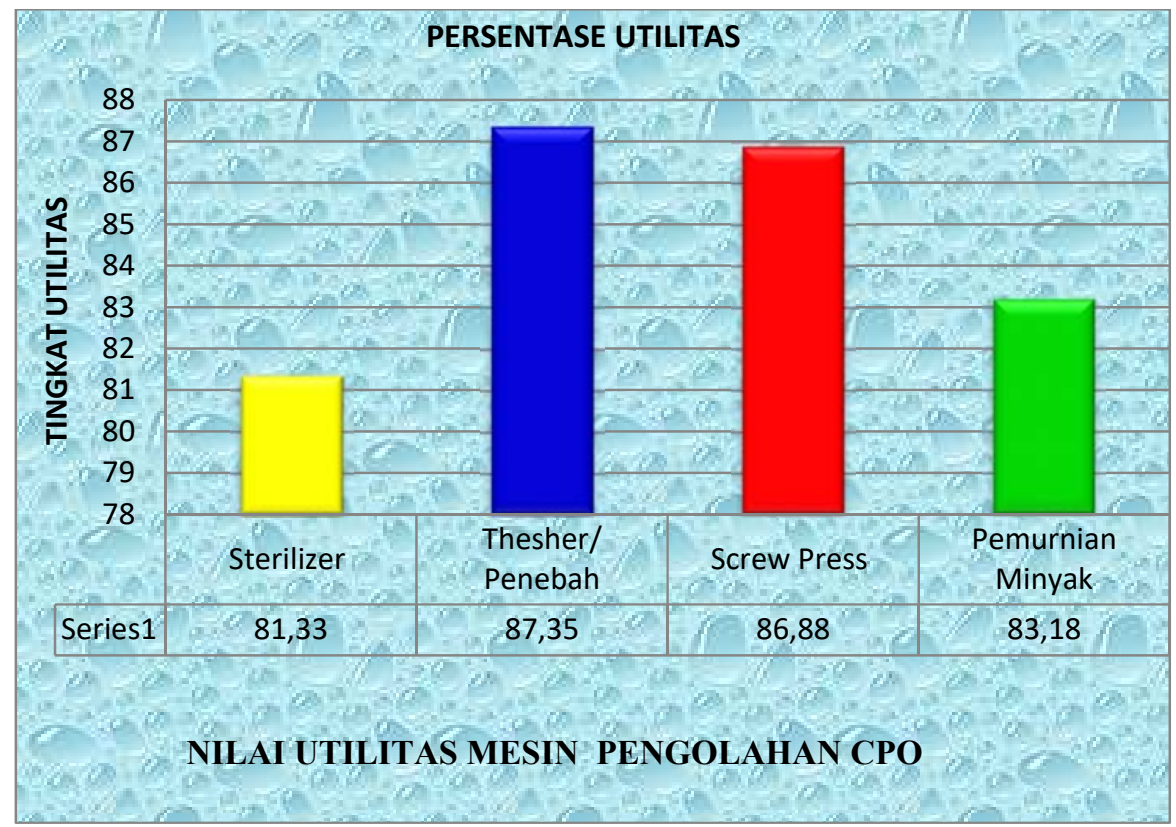

Gambar 3. Histogram Persentase Utilitas Keempat Mesin Pengolahan Tandan Buah Segar.

\subsection{Perhitungan Kapasitas Produksi}

Kapasitas merupakan ukuran batasan kemampuan dari suatu unit produk untuk memproduksi selama periode waktu tertentu, biasanya kapasitas dinyatakan dalam jumlah unit output per unit waktu. Kapasitas merupakan fungsi dari banyaknya sumber daya yang tersedia seperti peralatan, mesin, dan, jam kerja. Berdasarkan dari perhitungan kapasitas 
mesin untuk mesin sterilizer dengan kapasitas $81,33 \mathrm{Ton} / \mathrm{Jam}$, mesin thesher/penebah dengan kapasitas 45,08 Ton/Jam, mesin screw press dengan kapasitas 119,09 Ton/Jam, mesin pemurnian minyak 72,45 Ton/jam.

\subsection{Pembahasan}

\subsubsection{Waktu Standar}

Berdasarkan hasil perhitungan waktu standar pada setiap mesin pengolahan tandan buah segar bahwa nilai tertinggi yaitu pada stasiun pengepressan yaitu sebesar 155,16 menit sedangkan nilai terendah yaitu pada stasiun strelizer yaitu sebesar 122,80 menit. Tingginya waktu standar pada stasiun press disebabkan karena penggunaan waktu operasi yang kurang optimal dan seringnya mesin ini mengalami kerusakan pada komponen press sehingga dapat menurunkan tingkat performance kapasitas kinerja mesin press tersebut.

\subsubsection{Efisiensi Setiap Mesin}

Berdasarkan hasil perhitungan efisiensi pada setiap mesin pengolahan tandan buah segar bahwa nilai rata-rata efisien pada setiap mesin nilai tertinggi yaitu pada stasiun pengepressan yaitu sebesar $88,80 \%$ sedangkan nilai terendah yaitu pada stasiun pemurnian minyak yaitu sebesar $74,00 \%$. Rendahnya efisiensi pada stasiun pemurnian minyak disebabkan karena penggunaan waktu operasi yang kurang optimal dan seringnya mesin ini mengalami kerusakan pada komponen klep penyaringannya sehingga dapat menurunkan tingkat performance kapasitas kinerja mesin.

\subsubsection{Utilitas Setiap Mesin}

Berdasarkan hasil perhitungan utilitas pada setiap mesin pengolahan tandan buah segar nilai rata-rata utilitas mesin terbesar yaitu pada stasiun Thesher/Penebah yaitu sebesar $87,35 \%$, sedangkan nilai utilitas terendah yaitu pada stasiun Sterilizer yaitu sebesar $81,33 \%$ hal ini karena nilai utilitas pada mesin ini menunjukkan bahwa penggunaan waktu operasi yang kurang optimal dan mengalami bottleneck pada stasiun Sterilizer sehingga di perlukan alternatif untuk meningkatkan kapasitas yang tersedia dengan menambah jumlah lori sehingga produksi tidak akan terjadi bottleneck dan produksi dapat meningkat.

\subsubsection{Kapasitas Produksi}

Berdasarkan hasil perhitungan kapasitas olah pabrik dalam dua tahun terakhir dapat dilihat bahwa rata-rata kapasitas olah mesin berada pada 27,61 Ton/Jam sedangkan kapasitas olah mesin setelah dilakukan perhitungan adalah untuk mesin sterilizer dengan kapasitas 81,33 Ton/Jam, mesin thesher/penebah dengan kapasitas 45,08 Ton/Jam, mesin screw press dengan kapasitas 119,09 Ton/Jam, mesin pemurnian minyak 72,45 Ton/jam. Dengan rata-rata:

Kapasitas Olah Mesin Rata-Rata

$$
\begin{aligned}
& =\frac{\text { Kapasitas Mesin Strelilizer }+ \text { Theser } / \text { Penebah }+ \text { Screw Press }+ \text { Pemurnian Minyak }}{\text { Jumlah stasiun }} \\
& \quad \text { Kapasitas Mesin Olah Rata }- \text { Rata } \frac{81,33+45,08+119,09+72,45}{4}=\frac{317,95}{4} \\
& \text { Kapasitas Olah Mesin Rata-Rata }=79,48 \text { Ton/Jam }
\end{aligned}
$$


Optimisasi yang dilakukan adalah:

Optimisasi Kapasitas Olah = Kapasitas Hitung Rata-Rata - Kapasitas Pabrik Rata-Rata

$=79,48 \mathrm{Ton} / \mathrm{Jam}-27,61 \mathrm{Ton} / \mathrm{Jam}$

$=51,88 \mathrm{Ton} / \mathrm{Jam}$

\section{KESIMPULAN}

Setelah dilakukan pembahasan kembali maka diperoleh beberapa kesimpulan:

1. Waktu siklus yang diperlukan untuk mengolah 40 Ton tandan buah sawit pada mesin sterilizer adalah 1,96 Jam, untuk mesin thesher/penebah 2,07 Jam, untuk mesin screw press 2,48 Jam, dan mesin pemurnian minyak 2,00 Jam.

2. Waktu standar yang diperlukan untuk mengolah 40 Ton tandan buah sawit pada mesin sterilizer adalah 122,80 Menit/unit, untuk mesin thesher/penebah 129,47 Menit/unit, untuk mesin screw press 155,16 Menit/unit, dan mesin pemurnian minyak 125,19 Menit/unit.

3. Kapasitas olah mesin sterilizer adalah $65,91 \mathrm{Ton} / \mathrm{Jam}$, untuk mesin thesher/penebah adalah 49,76 Ton/Jam, untuk mesin screw press adalah 119,71 Ton/Jam, dan mesin pemurnian minyak adalah 38,53 Ton/Jam. Dengan optimisasi kapasitas olah sebesar $40,81 \mathrm{Ton} / \mathrm{Jam}$

\section{SARAN}

Saran yang dapat diberikan kepada pihak perusahaan adalah :

1. Untuk mengetahui apakah jadwal induk produksi ini dapat dilaksanakan dengan baik maka perusahaan dapat melakukan pengevaluasian setiap bulannya.

2. Pihak perusahaan dapat memberi perhatian yang khusus pada stasiun kerja bottleneck agar mesin atau peralatan pada stasiun kerja tersebut jangan sampai mengalami kerusakan.

3. Agar mesin produksi CPO berjalan dengan optimal maka sebaiknya pihak perusahaan melakukan perbaikan atau perawatan mesin secara berkala dan taratur untuk mengurangi kerusakan pada mesin yang menimbulkan tingginya jam stagnasi mesin. Tingginya jam stagnasi mesin akan berpengaruh terhadap efisiensi mesin dan kapasitas olah mesin dan yang nantinya akan berpengaruh pada jam kerja operator.

\section{PUSTAKA}

[1] Mangkunegara. 2009. Evaluasi Kinerja Sumber Daya Manusia. Bandung: Penerbit Refika Aditama.

[2] Daryanto. 1993. Dasar -Dasar Teknik Mesin. Rineka Cipta. Jakarta.

[3] Grant, L. 1996. Statistical Quality Control, Seventh Edition, McGraw-Hill.

[4] Tomi, Z. 2009. Aplikasi Ergonomi Dalam Menentukan Waktu Baku dan Kapasitas Pencurahan Setiap Bahan Baku, Poseding Seminar Nasional Aplikasi Program K3 \&Ergonomi di Tempat Kerja, Medan.

[5] Ralph M. B. 1968. Motion and Time Study : Design and Measurement of Work, Sixth Edition, Wiley International Edition. 
[6] Gasperz, V. 1998. Production and Inventory Control, PT. Gramedia Pustaka Utama, Jakarta.

[7] Handoko, H.T. 1984. Dasar-Dasar Manajemen Produksi dan Operasi, BPFE, Yogyakarta.

[8] Sinulingga, S. 2009. Perencanaan \& Pengendalian Produksi, Graha Ilmu, Medan 